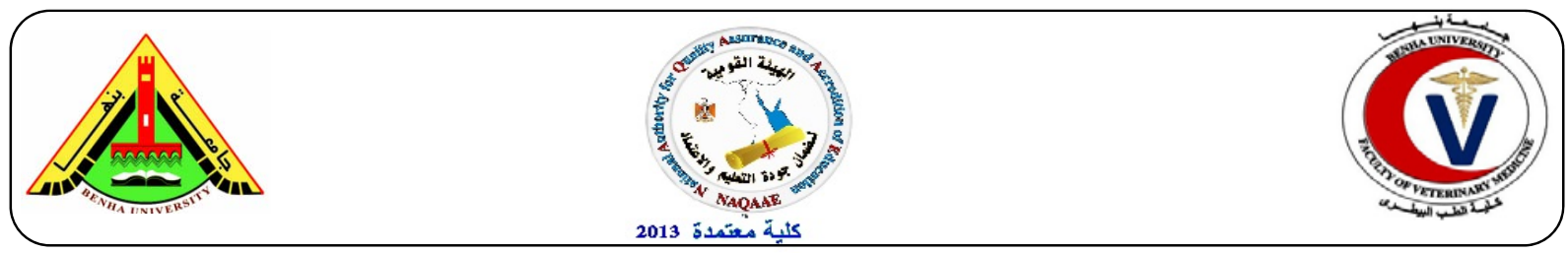

\title{
Protective Effect of Curcumin Against Adverse Effects of Meloxicam in Rats
}

\author{
El-Sayed, M.G.A. ${ }^{1}$; El-Komy, A.A.A. ${ }^{1}$ and Amany, Abd Al-Wahed ${ }^{2}$ \\ ${ }^{1}$ Department of Pharmacology, Faculty of Veterinary Medicine Benha University, Egypt \\ ${ }^{2}$ Dessouk Fever Hospital, Ministry of Health, Egypt
}

\begin{abstract}
A B S T R A C T
The aim of the present study was to determine the adverse effects of meloxicam on lipid profile, glucose profile and hematology as well as the protective effect of curcumin in rats. Thirty-six male Wister albino rats were randomly divided into main four groups; Group (1): control (administered saline only $0.5 \mathrm{ml}$ ); Group (2): meloxicam was administered intraperitoneally at level of $5.8 \mathrm{mg} / \mathrm{kg}$ body weight for 15 days; Group (3): curcumin extract was administered orally at level of $200 \mathrm{mg} / \mathrm{kg}$ body weight for 15 days; Group (4): were administered meloxicam intraperitoneally with oral administration of curcumin extract for 15 days. The findings revealed that there were significant increase in serum cholesterol level and serum triglycerides level of rat given meloxicam. There were significant decrease in serum cholesterol level and serum triglycerides of rats administered meloxicam with curcumin group. There was a significant increase in serum glucose level of rat given meloxicam. There was significant decrease in serum glucose level of meloxicam with curcumin group compared to meloxicam group. There was alteration in hematological parameters of rat given meloxicam. On the contrary, there was an improvement in hematological tests of meloxicam with curcumin group and improvement of histopathological study compared to meloxicam. On conclusion, administration of meloxicam intraperitoneally $5.8 \mathrm{mg} / \mathrm{kg}$ body weight resulted in impairment in lipid profile, glucose profile and hematological parameters and these impairments could be improved by curcumin administration.
\end{abstract}

Key words: Meloxicam; curcumin; lipid profile; glucose profile; blood pictures.

(http://www.bvmj.bu.edu.eg)

(BVMJ-33(2): 58-64, DECEMBER, 2017)

\section{INTRODUCTION}

Meloxicam is a derivative of oxicam and falls in the enolic acid group of non-steroidal antiinflammatory drugs. Nonsteroidal antiinflammatory drugs produce their mechanism of action through inhibition of cyclooxygenase, which is enzyme that synthesis prostaglandins (Vane and Botting, 1998). It has recently been postulated that anti-inflammatory efficacy of nonsteroidal anti-inflammatory drugs arises from inhibition of the cyclooxygenase- 2 isoform of cyclooxygenase, whereas inhibition of the cyclooxygenase-1 isoform produces the troublesome and sometimes serious gastric and renal side effects. A relatively selective cyclooxygenase- 2 inhibitor, such as meloxicam, may combine antiinflammatory efficacy with improved tolerability (Furst, 1997). The very low solubility of meloxicam in acidic environments suggests that meloxicam may cause few local gastrointestinal adverse events (Luger et al., 1996). The common known side effects of nonsteroidal anti-inflammatory drugs are stomach problems, kidney problems, high blood pressure or heart problems, fluid retention as swelling, around the lower legs, feet, ankles, and hands, rashes; or other allergic reactions (Henry, 1988). Curcuma longa is a perennial member of the Zingiberaceae family and is cultivated in India and other parts of Southeast Asia (Perrone et al., 2015). The primary active constituent of Curcuma longa and the responsible for its vibrant yellow color is curcumin. Curcumin induced numerous pharmacological activities, including antioxidant and antimicrobial properties (Jurenka, 2009). It has been proven that curcumin is a highly pleiotropic molecule which can be a modulator of intracellular signaling pathways that control cell growth, inflammation, and apoptosis. Curcumin might be a potential candidate for the prevention and/or treatment of some diseases due to its anti-oxidant, anti-inflammatory activities and an excellent safety profile (Noorafshan and Esfahani, 2012).

The aim of the present study was to investigate the adverse effect of meloxicam on lipid profile, 
glucose profile and hematology. The protective effect of curcumin was investigated in rats.

\section{MATERIALS AND METHODS}

\subsection{Drugs}

- Meloxicam $\left(\mathrm{C}_{14} \mathrm{H}_{13} \mathrm{~N}_{3} \mathrm{O}_{4} \mathrm{~S}_{2}\right)$, It is a derivative of oxicam and falls in the enolic acid group of nonsteroidal anti-inflammatory drugs obtained from Amriya for pharmaceutical industries, Alexandria, Egypt. It is dispensed as ampoules for intramuscular injection in concentration of $15 \mathrm{mg} / 2 \mathrm{ml}$.

- Curcumin is 1,7-Bis(4-hydroxy-3methoxyphenyl)-1,6-heptadiene 3,5-dione. It is the primary biologically active curcuminoid of Curcuma longa, a herbaceous perennial plant belonging to the ginger family (Zingiberaceae). It is used as $40 \%$ ethanolic extract obtained from National Research Center, Cairo, Eygpt.

\subsection{Animals}

Thirty-six male Wister albino rats weighting 200-250 g (age of rat 50 60 days) were used in the experimental investigation of these study. Rats were obtained from Animal House of Faculty of Veterinary Medicine, Benha University Egypt. They were fed fresh-pelleted food and their water was placed in glass bottles of $500 \mathrm{ml}$ capacity and provided adlipitum. Rats were kept at a constant environmental and nutritional condition throughout the period of experiment. Rats were left for 15 days for acclimatization before the beginning of the experiment.

\subsection{Experimental design}

Rats were randomly divided into 4 main groups. Group (1): Nine rats were administered $0.5 \mathrm{ml}$ of saline orally for 15 consecutive days and considered as control. Group (2): Nine rats were administered $5.8 \mathrm{mg} / \mathrm{kg}$ b.wt. of meloxicam intraperitoneally for 15 consecutive days. Group (3): Nine rats were administered $200 \mathrm{mg} / \mathrm{kg}$ b.wt. of curcumin extract orally for 15 consecutive days. Group (4): Nine rats were administered $5.8 \mathrm{mg} / \mathrm{kg}$ b.wt. of meloxicam intraperitoneally for 15 consecutive days and $200 \mathrm{mg} / \mathrm{kg}$ b.wt. of curcumin extract orally for 15 consecutive days.

\subsection{Blood samples}

Blood samples were taken at first, seventh and fourteenth day post-treatment in all groups after the end of administration of meloxicam, curcumin and meloxicam with curcumin. Blood samples were taken from each rats in the group for biochemical studies from median canthus of the eye. The first blood samples were collected without anticoagulant to obtain a clear serum for biochemical analysis. Serum samples were used for biochemical analysis to determine serum cholesterol level, serum triglycerides level and serum glucose level. The second blood samples were collected with ethylene diamine tetraacetic acid as anticoagulant. The sample was shaked in 8 figure shape several times to ensure mixing of the blood with anticoagulant. These blood samples were used for hematological studies to determine erythrocytic count, total leukocytic count, hemoglobin concentration and packed cell volume.

\subsection{Biochemical Analysis}

Stock and working solutions were maintained at $0^{\circ} \mathrm{C}$ in a refrigerator. Serum was obtained by high speed centrifugation. Serum chlesterol was determined enzymatically according to Allain et al., (1974). Serum triglycerides were determined according to Schettler and Nussel (1975). Serum glucose was determined by enzymatic method according to Trinder (1969).

\subsection{Hematological Analysis}

Erythrocytes were counted in the central square by a height power in the five large secondary squares ( 80 small tertiary squares). The large five squares were distributed over to whole counting chamber. One square from each corner and one in the central, counting include those touching the left and lower pine of the square. Leucocytes were counted in the whole central square. Hemoglobin was determined colorimetrically according to Wintrobe (1967). The packed cell volume was determined using the microhaematocrite method according to Cohen (1967).

\subsection{Statistical analysis}

The data were calculated as mean \pm standard error. All statistical analysis was carried out according to Berly and Lindgren (1990) using the following formulae:

$$
\begin{aligned}
& \bar{x}=\frac{\sum x}{n} \\
& \mathrm{SD}= \\
& \mathrm{S.E} .=\frac{\text { S.D. }}{\sqrt{n}}
\end{aligned}
$$

Where:

$\bar{x}=$ mean

$\Sigma \mathrm{x}=$ sum of values.

$\mathrm{n}=$ number of rat in each group.

S.D $=$ standard deviation from the mean.

$\Sigma\left(\overline{\left.x_{1}-x_{2}\right)}=\right.$ sum square difference of mean from value. 
S.E. $=$ Standard error of the mean.

The statistical analysis was done using SPPS (16) software (SPSS Inc., Chicago, USA). Duncan's multiple range test used to determine the differences between the averages.

\section{RESULTS}

\subsection{Effect on lipid profile}

Intraperitoneal administration of meloxicam (5.8 $\mathrm{mg} / \mathrm{kg}$ b.wt) for 15 days induced significant increase in serum cholesterol and triglycerides levels (Figure 1and 2). The effect of meloxicam on lipid profile can be improved by administration of curcumin.
Intraperitoneal administration of meloxicam (5.8 $\mathrm{mg} / \mathrm{kg}$ b.wt) for 15 days induced significant increase in serum glucose level (Figure 3). Administration of meloxicam together with curcumin significantly reduced the increase of serum glucose (Figure 3).

\subsection{Hematological effect:}

Intraperitoneal administration of meloxicam (5.8 $\mathrm{mg} / \mathrm{kg}$ b.wt) for 15 days caused no changes in the level of total erythrocytic count (Figure 4), induced significant increase in the level of total leukocytic count (Figure 5) and caused decrease in the concentration of the hemoglobin and Packed cell volume (Figure 6 and 7).

\subsection{Effect on glucose profile}

Effect of meloxicam (5.8 mg/kg body weight intraperitoneally for 15 days $)$ and curcumin $(200 \mathrm{mg} / \mathrm{kg}$ body weight orally for 15 days) on serum compared to control level in rats $(n=3)$.

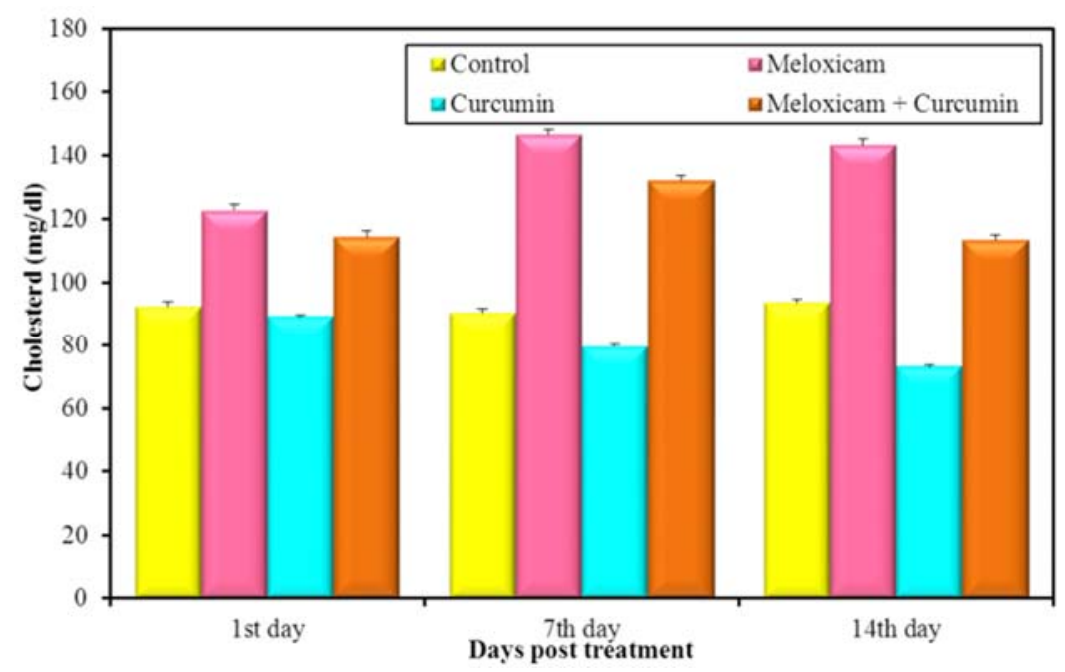

Figure (1)

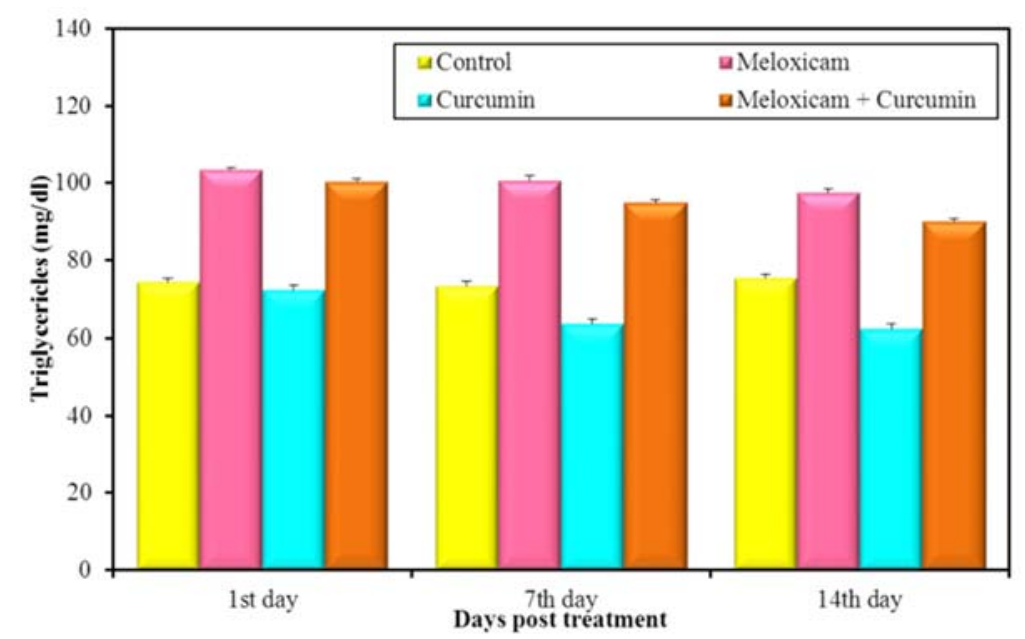


Figure (2)

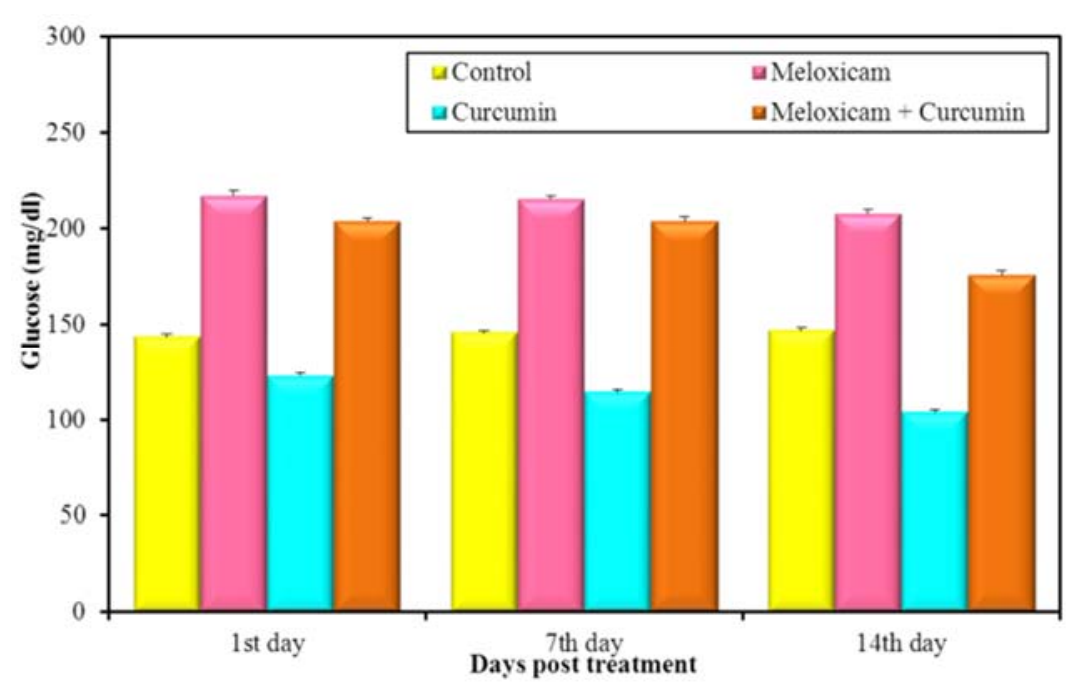

Figure (3)

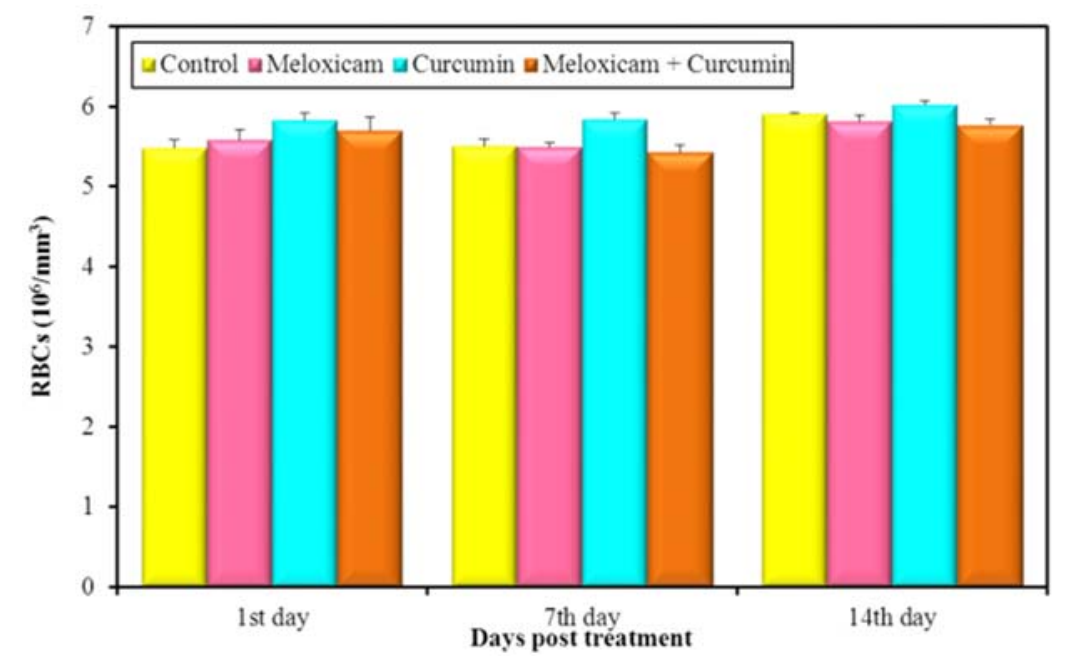

Figure(4)

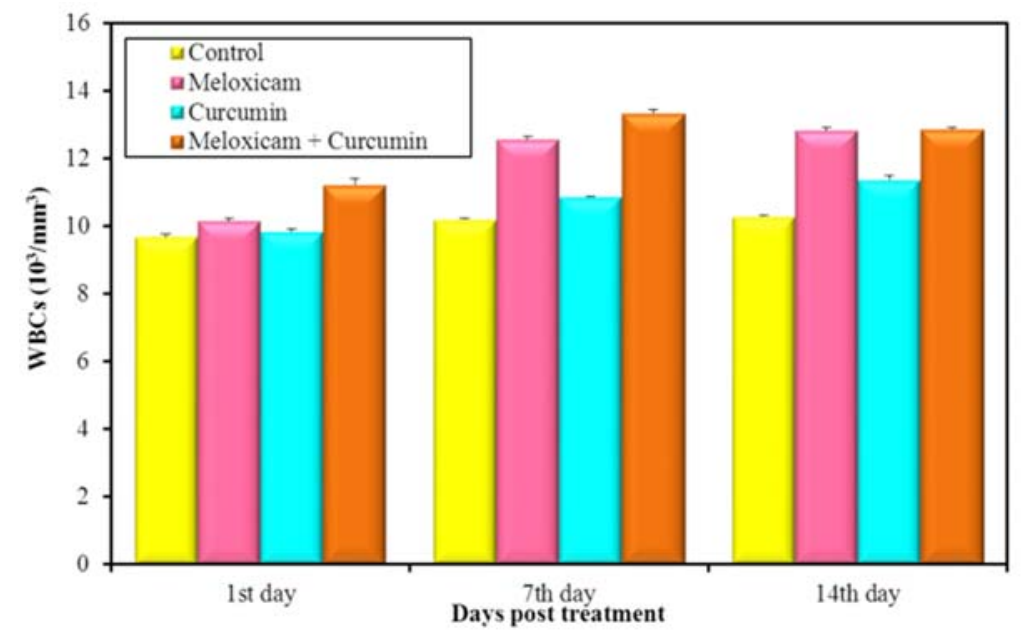

Figure (5) 

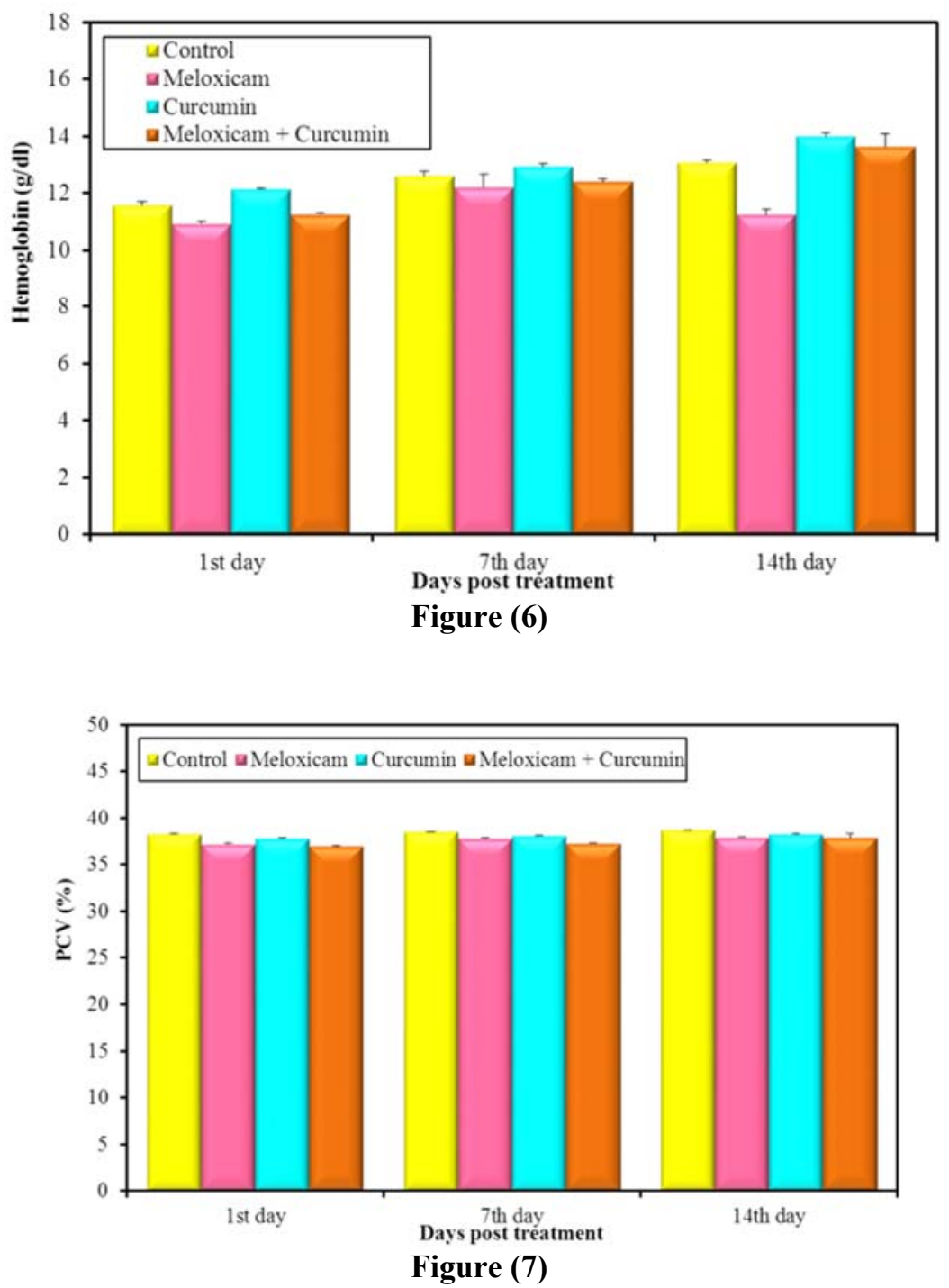

\section{DISCUSSION}

Meloxicam is one of nonsteroidal antiinflammatory drugs which has selective cyclooxygenase-2 inhibition. Curcumin the primary biologically active curcuminoid of Curcuma longa. It exhibits a variety of therapeutic properties, including antioxidant, analgesic, anti-inflammatory and antiseptic activities. The present study was designed to investigate the adverse effect of meloxicam and protective effect of curcumin.

Effect of meloxicam, curcumin and meloxicam with curcumin on lipid profile: serum cholesterol and triglycerides levels was studied. Meloxicam showed significant increase in level of serum cholesterol and triglycerides levels after intraperitoneal injection of meloxicam $(5.8 \mathrm{mg} / \mathrm{kg}$ body weight for 15 days) in rats. Orally administrated curcumin in a dose of $200 \mathrm{mg} / \mathrm{kg}$ body weight with intraperitoneal injection of meloxicam at $5.8 \mathrm{mg} / \mathrm{kg}$ body weight daily for 15 days showed significant decrease in serum cholesterol and triglycerides levels. The obtained results came in agreement with that obtained by Rao et al. (1970); Soudamini et al. (1992); Yasni et al. (1993); Hussain and Chandrasekhara (1994); Quiles et al., (1998); Kapoor et al. (2008); Jagadeesh et al. (2009) and Abdou et al. (2015).

Intraperitoneal injection of meloxicam at 5.8 $\mathrm{mg} / \mathrm{kg}$ body weight daily for 15 days in rats showed a significant increase in serum glucose level. Orally administrated curcumin in a dose of 200 $\mathrm{mg} / \mathrm{kg}$ body weight with intraperitoneal injection of meloxicam at $5.8 \mathrm{mg} / \mathrm{kg}$ body weight daily for 15 days showed significant decrease in glucose level compared to meloxicam treated group. This results were similar to that obtained by Jagadeesh et al. (2009). The effect of intraperitoneal injection of meloxicam at $5.8 \mathrm{mg} / \mathrm{kg}$ body weight daily for 15 days in rats showed no changes in the level of total erythrocytic count, significant increase in the 
level of total leukocytic count and significant decrease in the concentration of the hemoglobin and the level of packed cell volume. The obtained results were coming in agreement with that obtained by Al-Rekabi et al. (2009) and Busch et al. (1998).

Orally administrated curcumin in a dose of 200 $\mathrm{mg} / \mathrm{kg}$ body weight with intraperitoneal injection of meloxicam at $5.8 \mathrm{mg} / \mathrm{kg}$ body weight daily for 15 days showed significant increase in the level of total erythrocytic count, the concentration of the hemoglobin and the level of Packed cell volume and significant decrease in the level of total leukocytic count compared to meloxicam treated group.

\section{CONCLUSION}

In the present work, it was concluded that the intraperitoneal injection of meloxicam $(5.8 \mathrm{mg} / \mathrm{kg}$ body weight for 15 days) caused alterations in lipid profile, glucose profile and some hematological parameters. On other hand those effects of meloxicam can be resolved by oral administration of $200 \mathrm{mg} / \mathrm{kg}$ body weight of curcumin extract.

\section{REFERENCES}

Abdou, S.E.; Taha, N.M.; Mandour, A.A.; Lebda, M.A.; El Hofi, H.R. and El-Morshedy, A.M. (2015): Antifibrotic Effect of Curcumin on Thioacetamide Induced Liver Fibrosis. Alexandria Journal of Veterinary Sciences; 45: 43-50.

Allain, C.C.; Poon, L. S.; Chan, C. S. G.; Richmond and W., Fu, P. C. (1974): Enzymatic determination of total serum cholesterol. Clinical Chemistry; 20:470475.

Al-Rekabi, F.M.K.; Abbas, D.A. and Hadi, N.R. (2009): Effects of subchronic exposure to meloxicam on some hematological, biochemical and liver histopathological parameters in rats. Iraqi Journal of Veterinary Sciences; 23: 249-254.

Berly, D.A. And Lindgren, B.W. (1990): "Statistics: Theory and Methods". Brooksl cole publishing company, Pacific Grove California.

Busch, U.; Schmid, J.; Heinzel, G.; Schmaus, H.; Baierl, J.; Huber, C. and Roth, W. (1998): Pharmacokinetics of Meloxicam in Animals and The Relevance to Humans. Drug Metabolism and Disposition; 26(6): 576584.
Cohen, R.R. (1967): Anticoagulation, centrifugation time, and sample replicate number in the micro hematocrit method for avian blood. Poultry Science; 46 (1): 214218.

Furst, D.E. (1997): Meloxicam: Selective COX-2 inhibition in clinical practice. Elsevier; 126(6): 21-27.

Henry, D.A. (1988): Side-effects of non-steroidal anti-inflammatory drugs. Elsevier; 2(2): 425-454.

Hussain, M.S. and Chandrasekhara, N. (1994): Biliary proteins from hepatic bile of rats fed curcumin or capsaicin inhibit cholesterol crystal nucleation in supersaturated model bile, Indian Journal of Biochemistry and Biophysics; 31(5): 407-412.

Jagadeesh, M.C.; Sreepriya, M.; Bali, G. and Manjulakumari, D. (2009): Biochemical studies on the effect of curcumin and embelin during $\mathrm{N}$ - nitrosodiethylamine / phenobarbital induced hepatocarcinogenesis in wistar rats. African Journal of Biotechnology; 8 (18): 4618 4622.

Jurenka, J.S. (2009): Anti-inflammatory Properties of Curcumin, a Major Constituent of Curcuma longa: A Review of Preclinical and Clinical Research. Alternative Medicine Review; 14 (2):141-153.

Kapoor, P.; Ansari, M.N. and Bhandari, U. (2008): Modulatory effect of curcumin on methionine- induced hyperlipidemia and hyperhomocysteinemia in albino rats. Indian Journal of Experimental Biology; 46: 534540.

Luger, P.; Daneckb, K.; Engel, W.; Trummlitz, G. and Wagner, K. (1996): Structure and physicochemical properties of meloxicam, a new NSAID. Elsevier; 4(3): 175-187.

Noorafshan, A. And Ashkani-Esfahani, S. (2012): A eview of Therapeutic Effects of Curcumin. Research Gate; 19(11): 20322046.

Perrone, D.; Ardito, F.; Giannatempo, G.; Dioguardi, M.; Troiano, G.; Lo Russo, L.; De Lillo, A.; Laino, L. and Lo Muzio, L. (2015): Biological and therapeutic activities, and anticancer properties of curcumin (Review). Experimental and Therapeutic Medicine; 10(5): 1615-1623.

Quiles, J.L.; Aguilera, C.; Mesa, M.D.; RamirezTortosa, M.C.; Baro, L. and Gil, A. (1998 ): An ethanolic aqueous extract of Curcuma longa decreases the susceptibility of liver microsomes and mitochondria to lipid 
peroxidation in atherosclerotic rabbits. Biofactors; 8 (1-2): 51-57.

Rao, D.S.; Sekhara, N.C.; Satyanarayana, M.N. and Srinivasan, M. (1970): Effect of curcumin on serum and liver cholesterol levels in the rat. Jornal of Nutrition; 100(11): 1307-1315.

Schettler, G. And Nussel, E. (1975): Colorimetric method for determination of cholesterol activity. Arb. Sozial Med. Prav, MED. 1025.

Soudamini, K.K.; Unnikrishnan, M.C.; Soni, K.B. and Kuttan, R. (1992): Inhibition of lipid peroxidation and cholesterol levels in mice by curcumin, Indian Journal of Physiology and Pharmacology; 36 (4): 239-243.
Trinder, P.A. (1969): Colourimetric estimation of glucose concentration. Annals of Clinical Biochemistry; 6: 24.

Vane, J.R. and Botting, R.M. (1998): Antiinflammatory drugs and their mechanism of action. Inflammation Research; 47(2): 7887.

Wintrobe, M.W. (1967): Rrfereal methods for hemoglobin detection. Johns Hopkins medical Journal; 120(5): 287-309.

Yasni, S.; Imaizumi, K.; Nakamura, M.; Aimoto, J. and Sugano, M. (1993): Effects of Curcuma xanthorrhiza Roxb. and curcuminoids on the level of serum and liver lipids, serum apolipoprotein A-I and lipogenic enzymes in rats. Elsevier; 31(3): 213-218. 